\title{
Development of the system of visual control of electric power consumption by electric rolling stock
}

\author{
Stanislav Istomin ${ }^{1, *}$, Artem Perestenko ${ }^{1}$, and Cong Dang ${ }^{2}$ \\ ${ }^{1}$ Omsk State Transport University, 644046, Marx av., 35, Omsk, Russia \\ ${ }^{2}$ Dalian Jiaotong University, Dalian, China
}

\begin{abstract}
The paper considers the issue of organization of control of electric power consumption by electric rolling stock by visualizing information on the monitor of the driver's console. With the correct analysis of information coming on board of the electric rolling stock, the train driver makes correction of the driving modes of the train in terms of energy efficiency. In this paper, to visualize information on the efficiency of power consumption by an electric rolling stock on the route, the authors propose using an indicator diagram using a green, white, and orange gradient. The variant of output of the final information on the efficiency of power consumption of electrical energy by an electric rolling stock both within the distances operated by the locomotive crews and within the hauls to the monitor of the driver's console is presented. One of the main advantages of using the technology of visual control of electric power consumption by electric rolling stock is the promptness of correction of decision-making on the rational use of energy resources, the identification of objective reasons for the overspending of energy, and the identification of reference results for the driving of trains. The prospect of development of the research topic is the approbation and implementation of the proposed technical and technological solutions in the production, which will reduce the specific consumption and unproductive electric power losses within the boundaries of the railway accounting zones.
\end{abstract}

\section{Introduction}

JSC "Russian Railways" is one of the largest consumers of energy resources, which accounts for about $4.4 \%$ of all electricity produced in Russia, $85 \%$ of which is expended on traction, so the priority tasks of the energy strategy of the holding of JSC "Russian Railways" for the period until 2020 and for the future up to 2030 are: a qualitative improvement of the management structure of consumption of traction-energy resources (TER) based on the use of modern information technologies, accounting systems, regulation and monitoring of consumption of TER, and a significant increase of energy efficiency indicators of train traction [1]. In general for JSC "Russian Railways", the projected reduction in the specific consumption of TER for train traction by 2015 should be from 2.5 to $4.4 \%$ by 2020 and from

\footnotetext{
*Corresponding author: istomin_sg@mail.ru
} 
8.0 to $9.0 \%$ by 2030 , which can be achieved, in particular, by the implementation in practice of a method developed at the Omsk State Transport University for reducing the specific consumption and unproductive electric power losses within the boundaries of the railway accounting zones.

\section{Object and methods of research}

The method developed at the Omsk State Transport University is based on two options for organization of the control of electric power consumption by electric rolling stock (ERS):

1. On the data processing server;

2. On the board of ERS.

The first option allows localizing the accounting zones with increased specific consumption and unproductive electric power losses by the end of the day with specification by even and odd directions, by belonging to the locomotive depot, series and numbers of locomotives, and developing measures to increase the efficiency of using ERS energy at the distance operated by the locomotive crews.

This option takes into account unproductive electric power losses at non-scheduled stops, train delays at the red traffic lights, speed limits at the section, regaining of schedule time, down time on traction tracks of locomotive depots and turnaround stations, down time on the route and waiting for work, and also electric power losses associated with unsatisfactory technical condition of locomotives and the lack of use by drivers of rational driving modes of the train. The first option of the organization of control over the consumption of electric power of ERS was described in detail in the works [2-14].

The second option implies a visual representation of information on electric power consumption along the route that will allow the driver to perform a rapid analysis of his actions and will motivate him to use energy-efficient driving modes.

\section{Results}

The information is presented in the form of a scale indicator having the structure shown in Figure 1a.

The zero value corresponds to the lower border of the indicator. The following values are measured from it:

- the current consumption at this point of the route while making the best trip Wmin, reaching the value Wss when arriving at the terminal station of the section. This value is not displayed on the screen when $\mathrm{Wmin}=\mathrm{Wss}$ or $\mathrm{Wc} \geq \mathrm{Wss}$; 


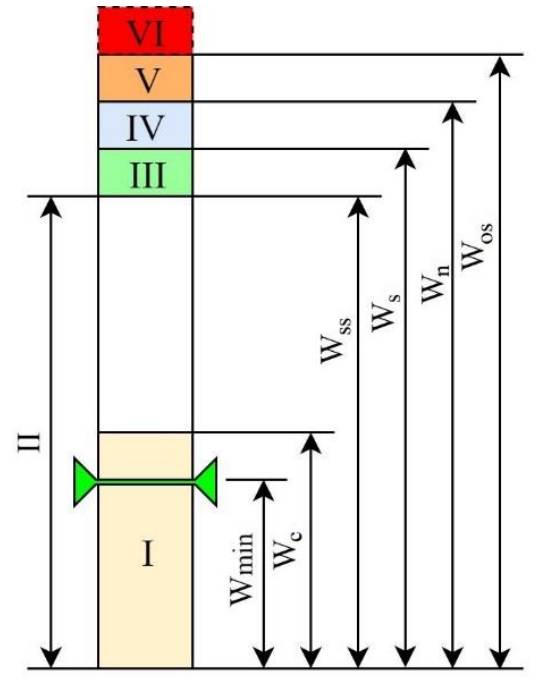

a

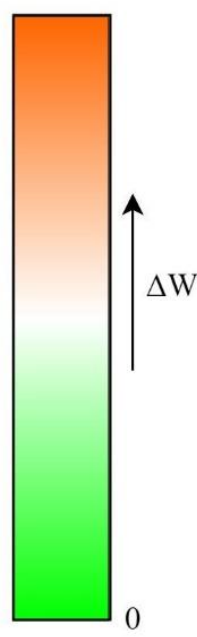

$\mathrm{b}$
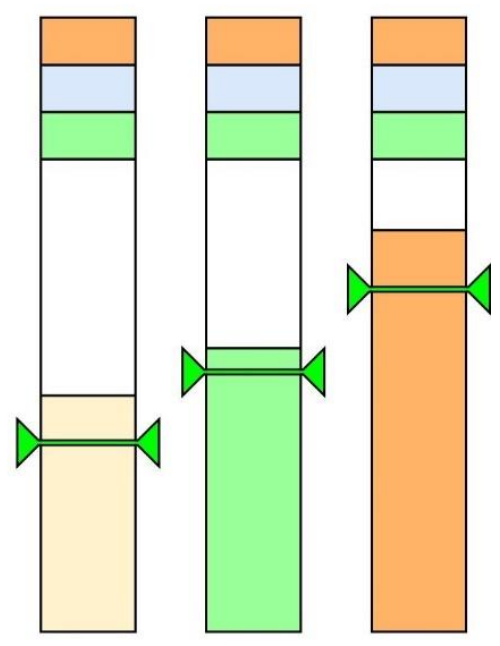

C

Fig. 1. Appearance of the energy consumption indicator: $a$ - the structure of the indicator, $b$ - an example of a color gradient, $\mathrm{c}-\mathrm{a}$ change in the color of the current consumption area with a change in $\Delta \mathrm{W}$.

- the current consumption Wc (non-decreasing value reaching the total value Wct when arriving at the terminal station of the section);

- the limit of super saving Wss (equal to the reduced best result of the passage through the current section);

- the limit of saving Ws (equal to the reduced worst result of the passage through the current section among the 100 best trips);

- norm Wn (equal to the norm established for this section);

- the limit of overspending Wos $=1,3 \cdot \mathrm{Wn}$;

The key values are $\mathrm{W}_{\min }$ and $\mathrm{W}_{\mathrm{t}}$. Estimating the relative position of the lines denoting these values, the driver can estimate the effectiveness of his actions in real time.

Let's consider the areas in more detail:

I. Area of current consumption: $\left[0, \mathrm{~W}_{\mathrm{c}}\right]$. The color of the area changes continuously and depends on the difference $\Delta \mathrm{W}=\mathrm{W}_{\mathrm{c}}-\mathrm{W}_{\min }$ : the lower values correspond to the color that causes the positive associations, the greater - to the color that causes the negative ones. According to the recommendations in [15], it is permissible to use the green-white-orange gradient shown in Fig. 1b. The relationship between the color of the area and $\Delta \mathrm{W}$ is shown in Figure 1c.

II. Area of super saving: [0, $\left.\mathrm{W}_{\mathrm{ss}}\right]$. If $\mathrm{W}_{\mathrm{ct}}$ belongs to this segment, then the section is passed with a super-high savings. This can happen due to the extremely high skill of the train driver or because of the abnormal operation conditions of ERS. These cases should be considered in detail to identify the causes of super saving and, if possible, their reproduction.

III. Area of saving: [ $\mathrm{W}_{\mathrm{ss}}, \mathrm{W}_{\mathrm{s}}$ ]. If $\mathrm{W}_{\mathrm{ct}}$ belongs to a given half-interval, then the section is passed with significant savings. If this result was obtained for the whole trip because of the skill of the train driver, then it will be included in the 100 best trips.

IV. Area of a norm: $\left[\mathrm{W}_{\mathrm{s}}, \mathrm{W}_{\mathrm{n}}\right]$. If $\mathrm{W}_{\mathrm{ct}}$ belongs to a given half-interval, then the section is passed without significant savings, but also without overspending.

V. Area of overspending: $\left[\mathrm{W}_{\mathrm{n}}, \mathrm{W}_{\mathrm{os}}\right]$. If $\mathrm{W}_{\mathrm{ct}}$ belongs to a given half- interval, then the section is passed in excess of the norm. This can happen both because of insufficiently high skill of the train driver and because of abnormal operation conditions of ERS. It is desirable 
to consider these cases to identify the causes of overspending and, if possible, to eliminate them.

VI. Area of burnout $\left[\mathrm{W}_{\mathrm{os}},+\infty\right]$. If $\mathrm{W}_{\mathrm{ct}}$ belongs to a given half-interval, then the section is passed with a significant excess of the norm. This can happen both because of the extremely low skill of the train driver and because of abnormal operation conditions of ERS. These cases should be considered in detail to identify the causes of burnout and, if possible, to eliminate them. This area is not displayed on the screen.

It is proposed to display two indicators at a time: the first one is for the trip as a whole; the second one is for the current haul. When $\mathrm{W}_{\mathrm{c}}$ enters area III, a short report on the results of the passing of the section is displayed on the indicators, examples of which are shown in Figure 2a. In the case of the indicator for haul, the report is displayed until the train crosses the border of the section, and then starts displaying information for the new haul.
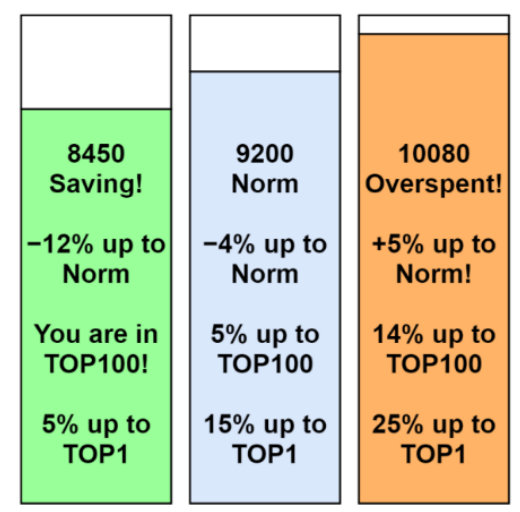

a
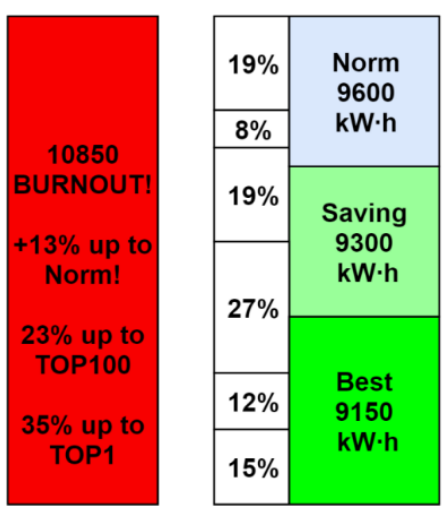

b

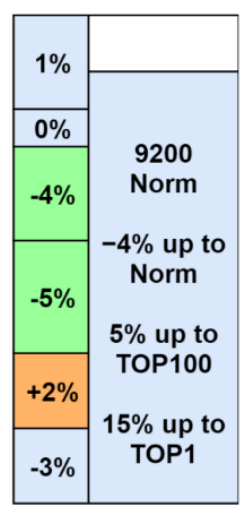

c

Fig. 2. Appearance of summary information about the trip, a - examples of reports with different energy consumption, $\mathrm{b}$ - information displayed before the beginning of the trip, $\mathrm{c}$ - final report on the trip.

The technology of visual control of energy consumption by the train driver can be represented in the form of the algorithm presented in Figure 3.

Block 1. The train driver at the workplace enters his personnel number.

Block 2. Using the available data, ERS requests and receives the following information from the servers:

- train route, which includes information about the start and end points and all planned stops;

- consumption rates for each haul and trip as a whole;

- detailed information on the dynamics of electric power consumption for the best trip on this route. 
Enter the DriverID

2

Getting information about the route and power consumption rates from the server

Displays the distribution of energy consumption between blocks and energy consumption rates per trip

4

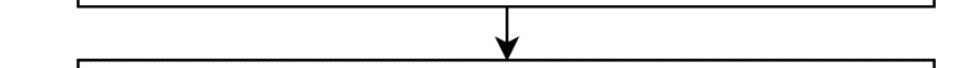

4

5

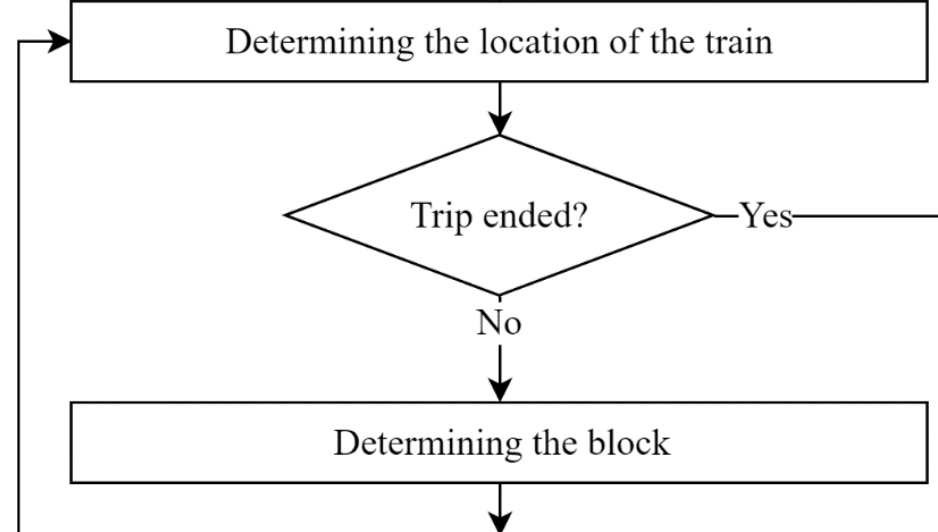

6

Displays the current energy consumption and energy consumption rates per block

7

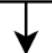

8

Displays the current energy consumption and energy consumption rates per trip

Displays the energy report per trip

10

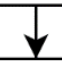

Sending data to the server

Fig. 3. Algorithm for controlling the energy consumption by the driver. 
Block 3. Before the trip, the general information on the trip is displayed on the screen (see Figure 2b), which includes the distribution of energy consumption by the hauls (left side) and the key values of energy consumption (right side): the super saving limit Wss ("Best result" in the figure), the limit of saving Ws, and the limit of the norm Wn.

Block 4. The locomotive determines its position in space through the systems of geolocation and the corresponding point of the route.

Block 5. On the basis of available data, it is determined whether the trip is completed.

Block 6. On the basis of available data, it is determined on which haul the train is located. 4).

Block 7. The indicator for the current haul is displayed (or updated) on the screen (Figure

Block 8. The indicator for the trip as a whole is displayed (or updated) on the screen (Figure 4).

Block 9. After the trip is over, a detailed report is displayed on the screen (see Figure 2c), consisting of information on the results for each haul (left part) and trip as a whole (right side).

Block 10. The information collected during the trip is sent to the server.

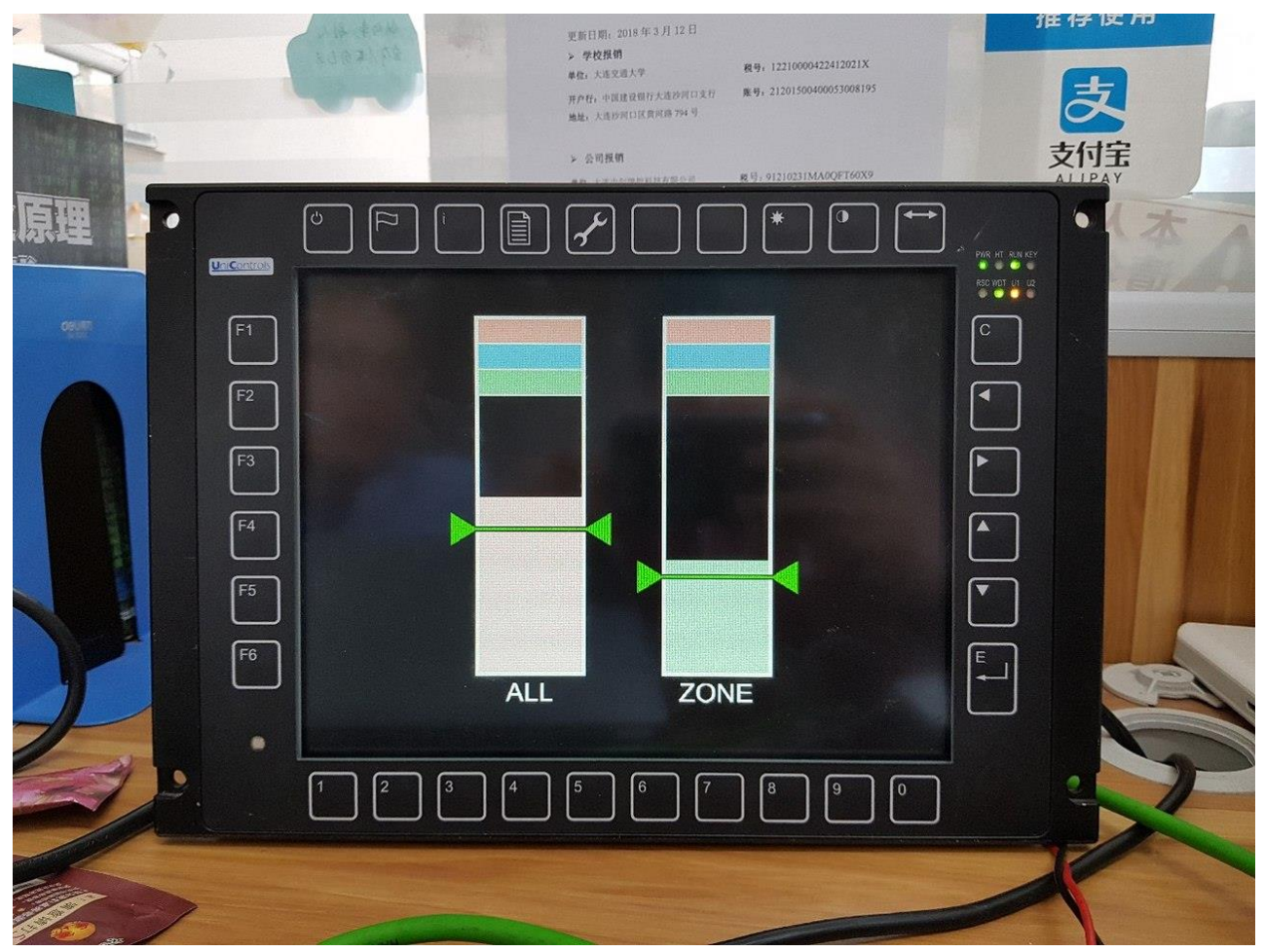

Fig. 4. Example of displaying the indicators on the monitor of the driver's console.

\section{Conclusions}

In conclusion, it should be noted that the implementation of visual control of the power consumption of EPS in practice will significantly reduce the specific consumption and unproductive electric power losses due to the continuous correction of the driving modes of trains along the route in terms of rational use of energy resources, which is essential for the development of the transport industry of the Russian Federation. 


\section{References}

1. V.A. Gapanovich, S.N. Epifantsev, V.A. Ovseichuk, The energy strategy and the electrification of Russian Railways (Eko-Press, Moscow, 2012)

2. S.G. Istomin, Izvestiya Transsiba, Omsk State Transport University 1(29), 64-74 (2017)

3. V.T. Cheremisin, O.V. Gateluk, S.G. Istomin, Scientific problems of transport in Siberia and the Far East, Novosibirsk state. acad. of water transport 2, 85 - 89 (2015)

4. V.T. Cheremisin, S.G. Istomin, Izvestiya Transsiba, Omsk State Transport University 2(22), 101-109 (2015)

5. V.T. Cheremisin, S. Yu. Ushakov, S.G. Istomin, Izvestiya Transsiba, Omsk State Transport University 1(21), 69-74 (2015)

6. S.G. Istomin, Vestnik RGUPS 2(58), 19-24 (2015)

7. V.T. Cheremisin, S.G. Istomin, A.L. Kashtanov, V.L. Nezevak, D.V. Pashkov, S. Yu. Ushakov, A. P. Shatokhin, Pat. 2591559 Russian Federation, IPC B 60 L 3/00. Method for determination of electric power losses by electric rolling stock at non-scheduled stops using onboard information and measurement systems of electricity metering (Omsk State Transport University, 2016)

8. V.T. Cheremisin, S.G. Istomin, D.V. Pashkov, S.Yu. Ushakov, Pat. 2591558 Russian Federation, IPC B 61 L 3/12. Method for determination of unproductive electric power losses by an electric rolling stock with the regaining of the scheduled time with the use of onboard information and measurement systems of electricity metering (Omsk State Transport University, 2016)

9. V.T. Cheremisin, D.V. Pashkov, S.Yu. Ushakov, S.G. Istomin, Pat. 2600960 Russian Federation, IPC V $60 \mathrm{~L}$ 3/12. Method for determination of unproductive electric power losses by an electric rolling stock during the passage of sections with a temporary speed limit using onboard information and measurement systems for electricity metering (Omsk State Transport University, 2016)

10. S.G. Istomin, Materials of scientific. conf., Omsk State Transport University, 55-62 (2016)

11. S.G. Istomin, Materials of All-Russian scientific conference with international participation, Omsk State Transport University, 15 - 22 (2016)

12. S. Istomin, V. Nesewak, Elektrische Bahnen 4, 186 - 189 (2015)

13. P. Treige, Elektrische Bahnen 8, 300 - 305 (2000)

14. S. Haaf, M. Kessner, Pat. 2534598 Russian Federation, IPC V 60 L 3/12. Computerbased control of energy consumption of means of transport (Siemens Aktiengesellschaft, 2014)

15. Russian Federation Standard GOST 12.4.026 2015 